\title{
Autologous Stem Cell Therapy in Critical Limb Ischemia: A Meta-Analysis of Randomized Controlled Trials
}

\author{
Baocheng Xie $\mathbb{D},{ }^{1}$ Houlong Luo $\left(\mathbb{D},{ }^{2}\right.$ Yusheng Zhang $\left(\mathbb{D},{ }^{1}\right.$ Qinghui Wang $\left(\mathbb{D},{ }^{1}\right.$ Chenhui Zhou $(\mathbb{D})^{3}$ \\ and Daohua $X u$ iD ${ }^{1,4}$ \\ ${ }^{1}$ Department of Pharmacology, Guangdong Medical University, Dongguan 523808, China \\ ${ }^{2}$ Institute of Laboratory Medicine, Guangdong Medical University, Dongguan 523808, China \\ ${ }^{3}$ School of Nursing, Guangdong Medical University, Dongguan 523808, China \\ ${ }^{4}$ Institute of Traditional Chinese Medicine and New Pharmacy Development, Guangdong Medical University, \\ Dongguan 523808, China
}

Correspondence should be addressed to Daohua Xu; daohuax108@163.com

Received 29 January 2018; Accepted 16 April 2018; Published 24 May 2018

Academic Editor: Kar Wey Yong

Copyright ( 2018 Baocheng Xie et al. This is an open access article distributed under the Creative Commons Attribution License, which permits unrestricted use, distribution, and reproduction in any medium, provided the original work is properly cited.

\begin{abstract}
Objective. Critical limb ischemia (CLI) is the most dangerous stage of peripheral artery disease (PAD). Many basic researches and clinical treatment had been focused on stem cell transplantation for CLI. This systematic review was performed to review evidence for safety and efficacy of autologous stem cell therapy in CLI. Methods. A systematic literature search was performed in the SinoMed, PubMed, Embase, ClinicalTrials.gov, and Cochrane Controlled Trials Register databases from building database to January 2018. Results. Meta-analysis showed that cell therapy significantly increased the probability of ulcer healing $(\mathrm{RR}=1.73$, 95\% $\mathrm{CI}=1.45-2.06)$, angiogenesis $(\mathrm{RR}=5.91,95 \% \mathrm{CI}=2.49-14.02)$, and reduced the amputation rates $(\mathrm{RR}=0.59,95 \%$ $\mathrm{CI}=0.46-0.76)$. Ankle-brachial index $(\mathrm{ABI})(\mathrm{MD}=0.13,95 \% \mathrm{CI}=0.11-0.15), \mathrm{TcO}_{2}(\mathrm{MD}=12.22,95 \% \mathrm{CI}=5.03-19.41)$, and pain-free walking distance $(\mathrm{MD}=144.84,95 \% \mathrm{CI}=53.03-236.66)$ were significantly better in the cell therapy group than in the control group $(P<0.01)$. Conclusions. The results of this meta-analysis indicate that autologous stem cell therapy is safe and effective in CLI. However, higher quality and larger RCTs are required for further investigation to support clinical application of stem cell transplantation.
\end{abstract}

\section{Introduction}

Critical limb ischemia (CLI) is the most dangerous stage of peripheral artery disease (PAD) caused by distal tissue hypoxia injury and lack of blood supply, including distal extremity ischemia, ulcers, or gangrene $[1,2]$. The prevalence of PAD in the general population is $3 \%$ to $10 \%[3,4]$. The data showed that $11.2 \%$ of patients with PAD would deteriorate to CLI each year, and the patient with CLI had the high amputation and mortality rates [5]. Currently, patients in PAD could be treated by percutaneous transluminal angioplasty (PTA) or intravascular thrombolysis [6, 7]; however, $10 \%-$ $30 \%$ of patients with CLI are not candidates for revascularization surgery. Many patients lose the chance of PTA, and the prognosis is poor after surgery, because the patients have peripheral atherosclerosis obliterans, extensive vascular disease, and/or serious damage caused by severe ischemic lesions of limbs $[8,9]$. The studies $[3,10]$ found that vascular remodeling and other means still cannot alleviate the symptoms of ischemia. The amputation rate is $10 \%-40 \%$, and the mortality rate is up to $20 \%$ in patients with CLI within 6 months [11]. The angiogenesis is the optimal treatment for CLI, and autologous stem cell therapy is an emerging alternative treatment $[12,13]$.

Since 2002, Tateishi-Yuyama et al. [14] have reported that bone marrow mononuclear cell transplantation was safe and effective for therapeutic angiogenesis in patients with CLI and it could significantly promote ulcer healing and reduce the amputation rate. During the past decades, a large number of basic researches and clinical treatment had been 
focused on stem cell transplantation for CLI [15]. The stem cell transplantation may improve pathophysiologic processes by stimulating the activities of tissue repair cells and inducing into vascular endothelial cells $[16,17]$. However, only few evidences were available regarding safety and efficacy of autologous stem cell therapy in CLI. Metaanalyses have already become supporting evidence-based medicine. Although, there were some meta-analyses of stem cell therapy in CLI, the small amount of studies or incomplete indicators lead to the results of deviation and unconvinced $[18,19]$. Therefore, this study of 23 RCTs with a total of 962 patients was included in order to acquire highquality evidence for the clinical efficacy and safety of autologous stem cell therapy in CLI.

\section{Methods}

2.1. Literature Search. We searched the clinical studies, including SinoMed, PubMed, Embase, http://ClinicalTrials. gov, and Cochrane Controlled Trials Register databases from building database to January 2018. Using the terms number 1 "stem cells," "mononuclear cells," "granulocyte colonystimulating factor," "G-CSF," "peripheral blood," and "bone marrow," the above search terms were connected with "OR". Number 2 "critical limb ischemia," "peripheral arterial disease," "peripheral vascular disease," "diabetic foot," "revascularization," "angiogenesis," or "arteriogenesis", the above search terms were connected with "OR". Number 3 "randomized controlled". Then, the above search terms of number 1 , number 2 , and number 3 were connected with "AND". We manually searched the references of the original and review articles for possible related studies.

2.2. Study Selection. For the systematic review, we searched 23 clinical studies that met the following criteria: (1) patients with PAD or CLI, (2) received autologous stem cell therapy, (3) reported as randomized controlled trials (RCTs), (4) the control group received standard therapy with or without sham injections, (5) at least 1-month follow-up, and (6) reported efficacy and safety issues.

2.3. Data Extraction and Quality Assessment. Two of the authors independently extracted the data of literature and made a quality assessment process according to the predefined inclusion criteria. Difference among the two authors was solved by discussion with the third author. We used the Cochrane risk of bias tool for the quality evaluation of the included studies. This quality evaluating strategy included criteria concerning aspects of random sequence generation, allocation concealment, blinding of participants and personnel, blinding of outcome assessors, incomplete outcome data, selective reporting, and other biases [20].

2.4. Statistical Analysis. In this meta-analysis, statistical analysis was performed using RevMan software version 5.3 and we used risk ratio (RR) with 95\% confidence interval (CI) for the analysis of dichotomous data, whereas the continuous data were presented as weighted mean difference (MD) or standardized mean difference (SWD) with 95\% CI. Heterogeneity between the studies was determined using the chi- square test, with the $I^{2}$ statistic, where $I^{2}<25 \%$ represent mild inconsistency, values between $25 \%$ and $50 \%$ represent moderate inconsistency and values $>50 \%$ suggest severe heterogeneity between the studies. We defined $I^{2}>50 \%$ as an indicator of significant heterogeneity among the trials. We used random effects' models to estimate the pooled results to minimize the influence of potential clinical heterogeneity among the studies, and the statistical significance was assumed at $P<0.05$. Subgroup analysis was assessed using the $\chi^{2}$ test. Sensitivity analysis was performed to evaluate the robustness of merged results, by removing individual study. Publication bias was assessed by means of funnel plots.

\section{Results}

3.1. Search Results. A systematic search of studies published until January 2018 was performed through SinoMed, PubMed, Embase, http://ClinicalTrials.gov, and Cochrane Controlled Trials Register databases from building database. A total of 1130 literatures were searched, 23 RCTs were included in the inclusion criteria, and the literature search procedure was shown in Figure 1.

3.2. Study Characteristics. The general characteristics of the included studies were listed in Table 1 . The included studies were 23 RCTs with a total of 962 patients. In these studies, the cell therapy group was one of the following stem cells: bone marrow mononuclear cells (BMMNCs, $n=7$ studies), bone marrow mesenchymal stem cells (BMMSCs, $n=4$ studies), bone marrow stem cells (BMSCs, $n=5$ studies), peripheral blood mononuclear cells (PBMNCs, $n=2$ studies), peripheral blood stem cells (PBSCs, $n=4$ studies), CD34+ ( $n=1$ study), or CD133+ stem cells ( $n=1$ study). The transplantation method of stem cell was intramuscular $(n=20$ studies) or intra-arterial ( $n=3$ studies). The patients in the control group received either placebo or standard care $(n=$ 23 studies). The dose of stem cells was divided into three groups: high dose $\left(10^{9}, n=5\right.$ studies $)$, medium dose $\left(10^{8}\right.$, $n=5$ studies), and low dose $\left(10^{7}, n=5\right.$ studies $)$. The mean follow-ups of the studies were 3 months ( $n=9$ studies), 6 months ( $n=8$ studies), and 12 months ( $n=3$ studies).

3.3. Quality Assessment. The risks of biases of the included studies were evaluated by the Cochrane assessment tool, and these results were summarized in Table 2. Three of the studies were at high risk of bias for blinding of participants and personnel and other biases according to the Cochrane Collaboration tool. Five studies reported methods of random sequence, and three studies reported the details of allocation concealment.

3.4. Amputation Rate. Amputation rate was reported in 18 studies with a total of 512 patients treated with cell therapy and 525 patients in the control groups (Figure 2). Cell therapy was associated with a significant $41 \%$ reduction in the amputation rate, compared with control groups $(\mathrm{RR}=0.59$, 95\% CI $=0.46-0.76, P<0.0001)$. Subgroup analyses indicated that peripheral blood stem cell (PBSC) was more beneficial than bone marrow stem cell (BMSC) on the amputation rate $\left(P=0.03, I^{2}=78.6 \%\right)$. Intramuscular of autologous stem 


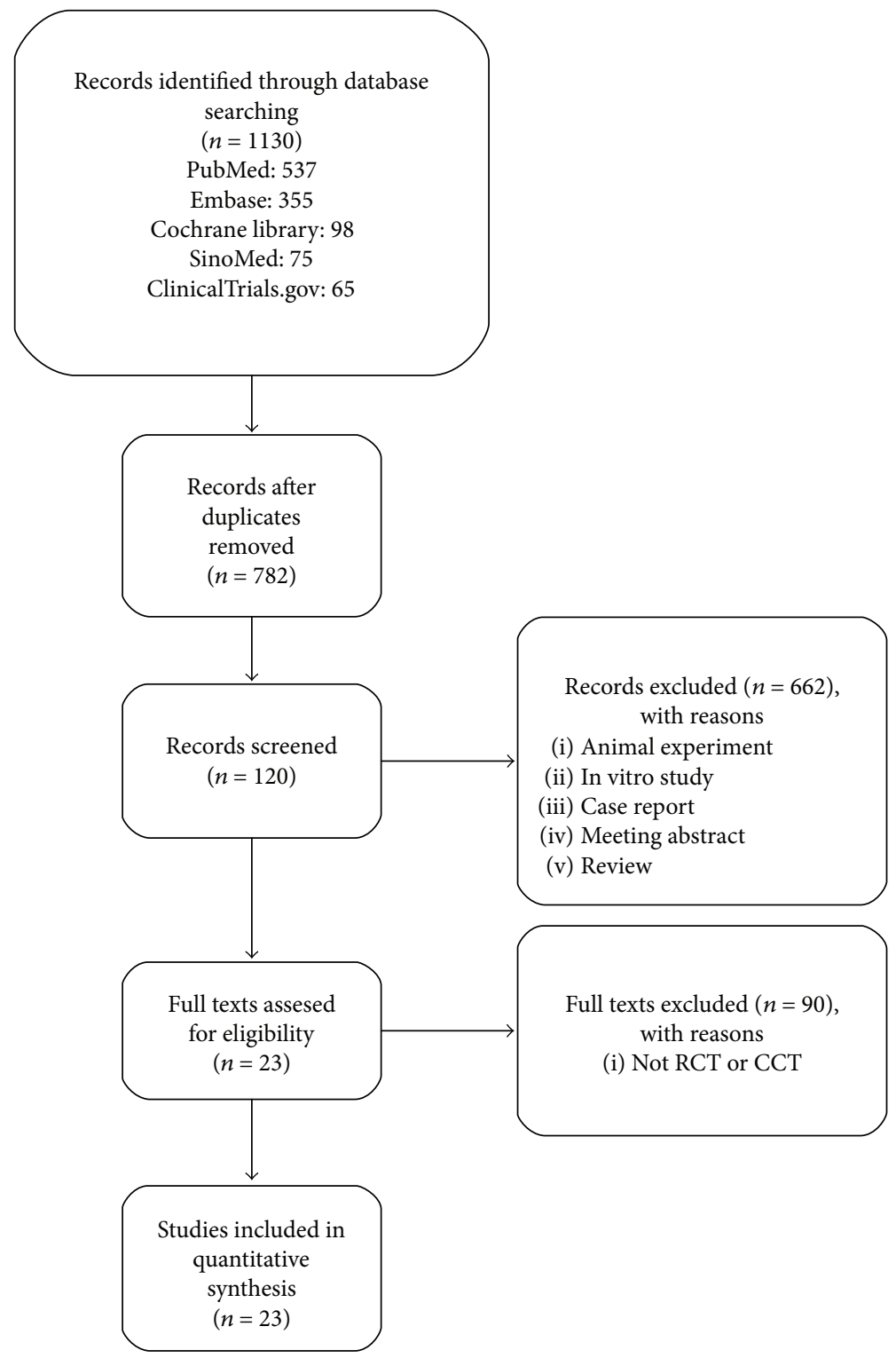

FIGURE 1: Flow chart and strategy of the meta-analysis.

cell transplantation was better than intra-arterial in reducing the amputation rate $\left(P=0.05, I^{2}=75 \%\right)$. The mean follow-ups of the studies were divided into 3 months, 6 months, and 12 months, and the group of 3 months was a significant difference compared with 6 months and 12 months $(P=0.03)$. Subgroup analysis among high dose $\left(10^{9}\right)$, medium dose $\left(10^{8}\right)$, and low dose $\left(10^{7}\right)$ showed that the group of low dose $\left(10^{7}\right)$ had a significant effect in reducing the amputation rate.

3.5. Ulcer Healing and Pain-Free Walking Distance. Ulcer healing was included in the analysis of 18 studies (Figure 3). Results of analysis showed that cell therapy could significantly increase the probability of ulcer healing $(\mathrm{RR}=1.73$, $95 \% \mathrm{CI}=1.45-2.06, P<0.00001)$. Subgroup analyses indicated that the low dose $\left(10^{7}\right)$ group of autologous stem cell transplantation was better than the other groups in ulcer healing $(\mathrm{RR}=3.55,95 \% \mathrm{CI}=1.95-6.48, P=0.02)$. Pain-free walking distance significantly increased in cell therapy $(\mathrm{MD}=144.84,95 \% \mathrm{CI}=53.03-236.66, P=0.002)$ (Figure 4$)$.

3.6. Ankle-Brachial Index (ABI) and Transcutaneous Oxygen Tension $\left(\mathrm{TcO}_{2}\right)$. ABI with 15 studies was included in the analysis (Figure 5). Results indicated that cell therapy significantly improved the $\mathrm{ABI}$ by $0.13(\mathrm{MD}=0.13,95 \% \mathrm{CI}=$ $0.11-0.15, P<0.00001)$. Subgroup analyses indicated that bone marrow mesenchymal stem cells (BMMSCs) were superior to bone marrow mononuclear cells (BMMNCs), but there was no significant difference between bone marrow stem cells (BMSCs) and peripheral blood stem cells (PBSCs) in improving the $\mathrm{ABI}$. The $\mathrm{TcO}_{2}$ with 8 studies was included in the analysis. Results indicated that cell therapy significantly improved $\mathrm{TcO}_{2}$ by $12.22 \mathrm{mmHg}(\mathrm{MD}=12.22,95 \%$ $\mathrm{CI}=5.03-19.41, P=0.0009)$. Subgroup analyses showed that there was no beneficial effect between BMSCs and PBSCs on the $\mathrm{TcO}_{2}$ (Figure 6). 
TABLE 1: Characteristics of included clinical studies.

\begin{tabular}{|c|c|c|c|c|c|c|c|c|}
\hline \multirow{2}{*}{ Study } & \multirow{2}{*}{$\begin{array}{l}\text { Sample } \\
(\mathrm{T} / \mathrm{C})\end{array}$} & \multirow{2}{*}{$\begin{array}{l}\text { Age } \\
(\mathrm{T} / \mathrm{C})\end{array}$} & \multicolumn{2}{|c|}{ Intervention } & \multirow{2}{*}{ Injection } & \multirow{2}{*}{ Follow-up } & \multirow{2}{*}{$\begin{array}{l}\text { Number } \\
\text { of cells }\end{array}$} & \multirow{2}{*}{ Evaluation } \\
\hline & & & $\mathrm{T}$ & $\mathrm{C}$ & & & & \\
\hline Huang et al. [37] & $14 / 14$ & $71.1 / 70.9$ & PBMNCs & Standard care & IM & $12 \mathrm{w}$ & $3 \times 10^{9}$ & (1), (2), (3), (4), (6), (7) \\
\hline Arai et al. [23] & $13 / 12$ & $62 / 68$ & BMMNCs & Standard care & IM & $1 \mathrm{mo}$ & $1-3 \times 10^{9}$ & (2), (5) \\
\hline Barć et al. [24] & $14 / 15$ & Unclear & BMMNCs & Standard care & IM & $6 \mathrm{mo}$ & Unclear & (1), (2) \\
\hline Lu et al. [38] & $22 / 23$ & $66.6 / 65.5$ & BMMSCs & Standard care & $\mathrm{IM}$ & $12 \mathrm{w}$ & $\begin{array}{l}7.32 \times 10^{8} \\
5.61 \times 10^{9}\end{array}$ & (1), (2), (3), (4), (6) \\
\hline Dash et al. [39] & $12 / 12$ & 40 & BMMSCs & Standard care & $\mathrm{IM}$ & $12 \mathrm{w}$ & $4.5-6 \times 10^{7}$ & (2), (6) \\
\hline Shi et al. [40] & $25 / 25$ & Unclear & BMSCs & Standard care & IM & $3 \mathrm{mo}$ & Unclear & (2), (4), (7) \\
\hline Procházka et al. [30] & $42 / 54$ & $66.2 / 64.1$ & BMSCs & Standard care & IA & $4 \mathrm{mo}$ & $1.96 \times 10^{8}$ & (1), (2), (3) \\
\hline Wen and Huang [34] & $30 / 30$ & 63 & PBSCs & Standard care & IM & $3 \mathrm{mo}$ & $3 \times 10^{9}$ & (1), (2), (3), (4), (7) \\
\hline $\mathrm{Lu}[15]$ & $21 / 41$ & 63 & BMMNCs & Standard care & IM & $24 \mathrm{w}$ & $9.3 \times 10^{8}$ & (1), (2), (3), (4), (5) \\
\hline Lu et al. [15] & $20 / 41$ & 65 & BMMSCs & Standard care & IM & $24 \mathrm{w}$ & $9.6 \times 10^{8}$ & (1), (2), (3), (4), (5) \\
\hline Walter et al. [25] & $19 / 21$ & $64.4 / 64.5$ & BMMNCs & Standard care & IA & $6 \mathrm{mo}$ & $1.53 \times 10^{8}$ & (1), (4), (5) \\
\hline Jain et al. [41] & $25 / 23$ & $54 / 58$ & BMSCs & Standard care & IM & $3 \mathrm{mo}$ & Unclear & (2) \\
\hline Benoit et al. [42] & $34 / 14$ & $65.7 / 72.5$ & BMSCs & Standard care & IM & $6 \mathrm{mo}$ & Unclear & (1), (2) \\
\hline Losordo et al. [43] & $16 / 12$ & $66.2 / 67.1$ & CD34+ & Standard care & IM & $12 \mathrm{mo}$ & $1 \times 10^{6} 1 \times 10^{5}$ & (1), (4) \\
\hline Powell et al. [44] & $48 / 24$ & $67.3 / 69.2$ & BMSCs & Standard care & IM & $12 \mathrm{mo}$ & $0.35-2.95 \times 10^{8}$ & (1) \\
\hline Ozturk et al. [31] & $20 / 20$ & $71.9 / 70.8$ & PBMNCs & Standard care & IM & $3 \mathrm{mo}$ & $2.48 \times 10^{7}$ & (1), (2), (3), (4), (5), (6) \\
\hline Gupta et al. [29] & $10 / 10$ & $43 / 47.6$ & BMMSCs & Standard care & IM & $6 \mathrm{mo}$ & $2 \times 10^{9}$ & (1), (2), (4) \\
\hline Li et al. [26] & $29 / 29$ & $61 / 63$ & BMMNCs & Standard care & IM & $6 \mathrm{mo}$ & $1 \times 10^{7}$ & (1), (2) \\
\hline $\begin{array}{l}\text { Mohammadzadeh } \\
\text { et al. [32] }\end{array}$ & $7 / 14$ & $63.5 / 64.2$ & PBSCs & Standard care & IM & $3 \mathrm{mo}$ & $2 \times 10^{7}$ & (1), (2), (4) \\
\hline Szabo et al. [33] & $10 / 10$ & $60.6 / 63$ & PBSCs & Standard care & IM & $24 \mathrm{mo}$ & $6.64 \times 10^{7}$ & (2), (5) \\
\hline Raval et al. [9] & $7 / 3$ & $65 / 85$ & CD133+ & Standard care & IM & $12 \mathrm{mo}$ & $5-40 \times 10^{7}$ & (1) \\
\hline Teraa et al. [5] & $81 / 79$ & $69 / 65$ & BMMNCs & Standard care & IA & $6 \mathrm{mo}$ & $5-6 \times 10^{8}$ & (1), (2), (4), (5) \\
\hline Skóra et al. [45] & $16 / 16$ & $66.7 / 68.3$ & BMMNCs & Pentoxifylline & IM & $3 \mathrm{mo}$ & $1.58 \times 10^{9}$ & (1), (3), (4) \\
\hline Lu et al. [46] & $20 / 21$ & 67.2 & PBSCs & Standard care & IM & $6 \mathrm{mo}$ & Unclear & (4), (5) \\
\hline
\end{tabular}

Note: $\mathrm{T}=$ cell therapy; $\mathrm{C}=$ control group; $\mathrm{IM}=$ intramuscular; $\mathrm{IA}=$ intra-arterial; $\mathrm{w}=$ week; $\mathrm{mo}=$ month; $\mathrm{PBMNCs}=$ peripheral blood mononuclear cells; BMMNCs = bone marrow mononuclear cells; $\mathrm{BMMSCs}=$ bone marrow mesenchymal stem cells; BMSCs = bone marrow stem cells; PBSCs = peripheral blood stem cells; (1) = amputation; (2) = ulcer healing; (3) = angiographic; (4)= $\mathrm{ABI}$; (5) = $\mathrm{TcO}_{2}$; (6) = pain-free walking distance; (7) = the blood flow of 10 toes.

3.7. Angiogenesis and Blood Flow of 10 Toes. There were 8 studies included in the analysis with angiogenesis (Figure 7). Analysis by digital subtraction angiography revealed that autologous stem cell transplantation significantly improved the new vessel form $(R R=5.91,95 \%$ $\mathrm{CI}=2.49-14.02, P<0.0001)$. The number of ischemic limbs with rich new collateral vessels in the transplant patients was significantly higher than that in the control group. Meanwhile, the blood flow of 10 toes significantly increased in cell therapy $(\mathrm{SMD}=0.83,95 \% \mathrm{CI}=0.48-1.18$, $P<0.00001$ ) (Figure 8).

3.8. Publication Bias and Heterogeneity. According to this meta-analysis, the significant symmetry showed that the ABI did not have obvious publication bias. Furthermore, the Egger's test funnel plot also indicated that there was no obvious publication bias in the ABI $(P>0.363,95 \% \mathrm{CI}=$ $-0.57-1.45$ ) (Figure 9). Sensitivity analysis was performed using a Galbraith plot for all the indicators. The results showed that there was no substantial change in the ABI and amputation rate, indicating that the results of meta-analysis were credible (Figure 10).

\section{Discussion}

4.1. Main Outcome. The registrations of stem cell clinical trials were retrieved on USA National Institutes of Health (NIH) clinical trial registration website (http://ClinicalTrials .gov). We performed the databases from building database to January 2018. There were 4715 clinical trial registration information for stem cells all over the world, and there were 2399 studies in America, 1027 studies in Europe, and 574 studies in China. We analyzed the disease of stem cell therapy and found that there were 1767 studies on neoplasms by histologic type, 1279 studies on immune system diseases, 607 studies on vascular diseases, and 513 studies on bone marrow diseases. The data showed that stem cell therapy has been used in various diseases, and stem cell therapy is approved in the globe. This meta-analysis included 23 RCTs with a total of 962 patients with CLI who were ineligible for surgical or percutaneous revascularization. Results indicated that autologous stem cell therapy had the potential effect to reduce the risk of amputation by $41 \%$ and significantly increased the probability effect of ulcer healing by $73 \%$ compared with the control group. $\mathrm{ABI}$ and $\mathrm{TcO}_{2}$ are the basic 
TABLE 2: Cochrane risk of bias assessment.

\begin{tabular}{|c|c|c|c|c|c|c|c|}
\hline Study & $\begin{array}{c}\text { Random } \\
\text { sequence } \\
\text { generation }\end{array}$ & $\begin{array}{c}\text { Allocation } \\
\text { concealment }\end{array}$ & $\begin{array}{l}\text { Blinding of } \\
\text { participants } \\
\text { and personnel }\end{array}$ & $\begin{array}{c}\text { Blinding } \\
\text { of outcome } \\
\text { assessment }\end{array}$ & $\begin{array}{l}\text { Incomplete } \\
\text { outcome data }\end{array}$ & $\begin{array}{l}\text { Selective } \\
\text { reporting }\end{array}$ & $\begin{array}{l}\text { Other } \\
\text { biases }\end{array}$ \\
\hline Huang et al. [37] & Unclear & Unclear & Unclear & Unclear & Low & Unclear & Low \\
\hline Arai et al. [23] & Unclear & Unclear & High & Unclear & Low & Low & Low \\
\hline Barć et al. [24] & Unclear & Unclear & High & Unclear & Low & Low & Low \\
\hline Lu et al. [38] & Unclear & Unclear & Unclear & Unclear & Low & Low & Low \\
\hline Dash et al. [39] & Unclear & Unclear & High & Unclear & Low & Unclear & Low \\
\hline Shi et al. [40] & Unclear & Unclear & High & Unclear & Low & Low & High \\
\hline Procházka et al. [30] & Low & Low & High & Unclear & Low & Low & Low \\
\hline Wen and Huang [34] & Unclear & Unclear & Unclear & Unclear & Low & Low & High \\
\hline $\mathrm{Lu}[15]$ & Unclear & Unclear & Low & Unclear & Low & Unclear & Low \\
\hline Lu et al. [15] & Low & Unclear & Low & Low & Low & Low & Low \\
\hline Walter et al. [25] & Unclear & Unclear & Low & Unclear & Low & Unclear & Low \\
\hline Jain et al. [41] & Low & Low & Low & Unclear & Low & Unclear & Low \\
\hline Benoit et al. [42] & Unclear & Unclear & Low & Unclear & Low & Low & Low \\
\hline Losordo et al. [43] & Unclear & Unclear & Low & Low & Low & Unclear & Low \\
\hline Powell et al. [44] & Unclear & Unclear & Low & Unclear & Low & Unclear & Low \\
\hline Ozturk et al. [31] & Unclear & Unclear & High & Unclear & Low & Low & Low \\
\hline Gupta et al. [29] & Low & Low & Low & Low & Low & Low & Low \\
\hline Li et al. [26] & Unclear & Unclear & Unclear & Unclear & Low & Unclear & Low \\
\hline Mohammadzadeh et al. [32] & Unclear & Unclear & Unclear & Unclear & Low & Low & Low \\
\hline Szabo et al. [33] & Unclear & Unclear & High & Low & Low & Low & Low \\
\hline Raval et al. [9] & Unclear & Unclear & Low & Low & Low & Low & Low \\
\hline Teraa et al. [5] & Low & Unclear & Low & Low & Low & Low & Low \\
\hline Skóra et al. [45] & Low & Unclear & Low & Low & Low & Low & Low \\
\hline Lu et al. [46] & Unclear & Unclear & High & Low & Low & Low & High \\
\hline
\end{tabular}

Note: low = low risk of bias; unclear $=$ unclear risk of bias; high $=$ high risk of bias.

indicators of CLI, and the results indicated that cell therapy significantly improved the $\mathrm{ABI}$ by 0.13 and $\mathrm{TcO}_{2}$ by $12.22 \mathrm{mmHg}$. Moreover, the value of the increased $\mathrm{ABI}$ and $\mathrm{TcO}_{2}$ level were meaningful to confirm the truth of the improvements of amputation and wound healing rates. In addition, cell therapy could improve the endpoints of limb perfusion, and the blood flow of 10 toes significantly increased in cell therapy, compared with the control group. We speculated that the main reason for the increases of limb perfusion was angiogenesis. The studies reported that endothelial progenitor cells (EPCs) derived from the bone marrow can facilitate microvasculature regeneration by paracrine or direct mechanisms in regions of blood vessel formation $[21,22]$. Therefore, we made a statistics on the use of angiography in patients with CLI. There were 8 studies with RCTs in the analysis, revealing a significant effect of angiogenesis after autologous stem cell transplantation.

4.2. Subgroup Analysis. A study by Tateishi-Yuyama et al. [14] reported that transplantation of bone marrow stem cell therapy in patients with CLI significantly improved $\mathrm{TcO}_{2}$, $\mathrm{ABI}$, and pain-free walking distance. Hereafter, many studies with RCTs had investigated the safety and feasibility of autologous stem cells of BMMNC therapy in CLI [5, 15, 23-26]. In recent years, a variety of cell types have been studied for treatment of PAD or CLI, including PBSCs, BMSCs, BMMNCs, PBMNCs, and BMMSCs. Our subgroup analyses indicated that PBSCs were more beneficial than BMSCs on the amputation rates. Dubsky et al. [13, 27] suggested that there was no significant difference in long-term prognosis between patients treated with BMMNCs and those treated with PBMNCs. The trials reported that transplantation of BMMSCs was safe and no serious adverse events by cell injection after the follow-up period [28, 29]. RCTs by Lu et al. [15] suggested that ulcer healing, $\mathrm{ABI}, \mathrm{TcO}_{2}$, painless walking time, and magnetic resonance angiography (MRA) in the BMMSC group were significantly higher than that in the BMMNC group in diabetic patients with CLI. The subgroup analyses indicated that BMMSCs showed beneficial effect than BMMNCs in improving the ABI. Therefore, BMMSCs could be more effective than BMMNCs in the treatment of CLI.

In RCTs of patients with CLI, the most common route of stem cell therapy administration was intramuscular. But, the potential route of intra-arterial was also injected therapy $[5,25,30]$. In order to find suitable and beneficial injection therapy, we conducted subgroup analysis. The results showed that the amputation rate in the intramuscular group was significantly lower than that in the intra-arterial group. The 


\begin{tabular}{|c|c|c|c|c|c|c|c|c|c|c|}
\hline \multirow{2}{*}{$\frac{\text { Study or subgroup }}{2.1 .1 \text { BMSCs }}$} & \multicolumn{2}{|c|}{ Cell therapy } & \multicolumn{2}{|c|}{ Control group } & \multirow[t]{2}{*}{ Weight } & \multirow[t]{2}{*}{$\begin{array}{c}\text { Risk ratio } \\
\mathrm{M}-\mathrm{H} \text {, fixed, } 95 \% \mathrm{CI}\end{array}$} & \multicolumn{4}{|c|}{$\begin{array}{c}\text { Risk ratio } \\
\text { M-H, fixed, 95\% CI }\end{array}$} \\
\hline & Events & Total & Events & Total & & & & & & \\
\hline Benoit et al. (2011) & 10 & 34 & 5 & 14 & $5.3 \%$ & $0.82(0.34,1.97)$ & & & - & \\
\hline Gupta et al. (2013) & 3 & 10 & 2 & 10 & $1.5 \%$ & $1.50(0.32,7.14)$ & & & & \\
\hline Li et al. (2013) & 3 & 29 & 5 & 29 & $3.8 \%$ & $0.60(0.16,2.28)$ & & & - & \\
\hline Losordo et al. (2012) & 7 & 16 & 9 & 12 & $7.7 \%$ & $0.58(0.31,1.11)$ & & $\rightarrow$ & & \\
\hline Lu et al. (2008) & 0 & 22 & 3 & 23 & $2.6 \%$ & $0.15(0.01,2.73)$ & & & & \\
\hline Lu et al. (2011) & 0 & 19 & 6 & 37 & $3.4 \%$ & $0.15(0.01,2.46)$ & & & & \\
\hline Lu et al. (2011) & 0 & 18 & 6 & 37 & $3.3 \%$ & $0.15(0.01,2.59)$ & & & & \\
\hline Piotr et al. (2006) & 3 & 14 & 7 & 15 & $5.1 \%$ & $0.46(0.15,1.44)$ & & & - & \\
\hline Powell et al. (2012) & 10 & 48 & 6 & 24 & $6.0 \%$ & $0.83(0.34,2.02)$ & & & 一 & \\
\hline Procházka et al. (2010) & 9 & 42 & 24 & 54 & $15.8 \%$ & $0.48(0.25,0.92)$ & & - & & \\
\hline Raval et al. (2014) & 3 & 29 & 5 & 29 & $3.8 \%$ & $0.60(0.16,2.28)$ & & & - & \\
\hline Skóra et al. (2015) & 4 & 16 & 8 & 16 & $6.0 \%$ & $0.50(0.19,1.33)$ & & & - & \\
\hline Teraa et al. (2015) & 21 & 81 & 19 & 79 & $14.5 \%$ & $1.08(0.63,1.85)$ & & & - & \\
\hline Walter et al. (2011) & 4 & 19 & 2 & 21 & $1.4 \%$ & $2.21(0.46,10.73)$ & & 3 & & \\
\hline Subtotal $(95 \% \mathrm{CI})$ & & 397 & & 400 & $80.1 \%$ & $0.67(0.52,0.87)$ & & $\bullet$ & & \\
\hline Total events & 77 & & 107 & & & & & & & \\
\hline Heterogeneity: $X^{2}=11.82, \mathrm{df}=$ & $P=0.54$ & ), $I^{2}=0 \%$ & & & & & & & & \\
\hline Test for overall effect: $Z=3.01$ & $=0.003)$ & & & & & & & & & \\
\hline 2.1.2 PBSCs & & & & & & & & & & \\
\hline Huang et al. (2005) & 0 & 23 & 5 & 24 & $4.1 \%$ & $0.09(0.01,1.62)$ & & & - & \\
\hline Mohammadzadeh et al. (2013) & 0 & 7 & 7 & 14 & $3.9 \%$ & $0.13(0.01,1.92)$ & & & - & \\
\hline Ozturk et al. (2012) & 3 & 20 & 5 & 20 & $3.8 \%$ & $0.60(0.17,2.18)$ & & & & \\
\hline Szabo et al. (2013) & 2 & 10 & 6 & 10 & $4.5 \%$ & $0.33(0.09,1.27)$ & & & & \\
\hline Wen and Huang (2010) & 1 & 55 & 5 & 57 & $3.7 \%$ & $0.21(0.03,1.72)$ & & & - & \\
\hline Subtotal $(95 \%$ CI) & & 115 & & 125 & $19.9 \%$ & $0.27(0.12,0.59)$ & & & & \\
\hline Total events & 6 & & 28 & & & & & & & \\
\hline $\begin{array}{l}\text { Heterogeneity: } X^{2}=2.45, \mathrm{df}=4 \\
\text { Test for overall effect: } Z=3.27\end{array}$ & $\begin{array}{l}=0.65) \text {, } \\
0.001)\end{array}$ & $I^{2}=0 \%$ & & & & & & & & \\
\hline Total $(95 \% \mathrm{CI})$ & & 512 & & 525 & $100.0 \%$ & $0.59(0.46,0.76)$ & & 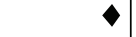 & & \\
\hline Total events & 83 & & 135 & & & & & & & \\
\hline $\begin{array}{l}\text { Heterogeneity: } X^{2}=17.81, \mathrm{df}= \\
\text { Test for overall effect: } Z=4.20 \\
\text { Test for subgroup differences: }\end{array}$ & $\begin{array}{l}P=0.47 \\
=0.001) \\
4.67, \mathrm{df}\end{array}$ & ), $I^{2}=0 \%$ & $0.03), I^{2}$ & & & & 0.005 & $\begin{array}{cc}0.1 & 1 \\
\text { Cell therapy }\end{array}$ & $\begin{array}{lr}1 & 10 \\
& \text { Control g }\end{array}$ & group \\
\hline
\end{tabular}

(a)

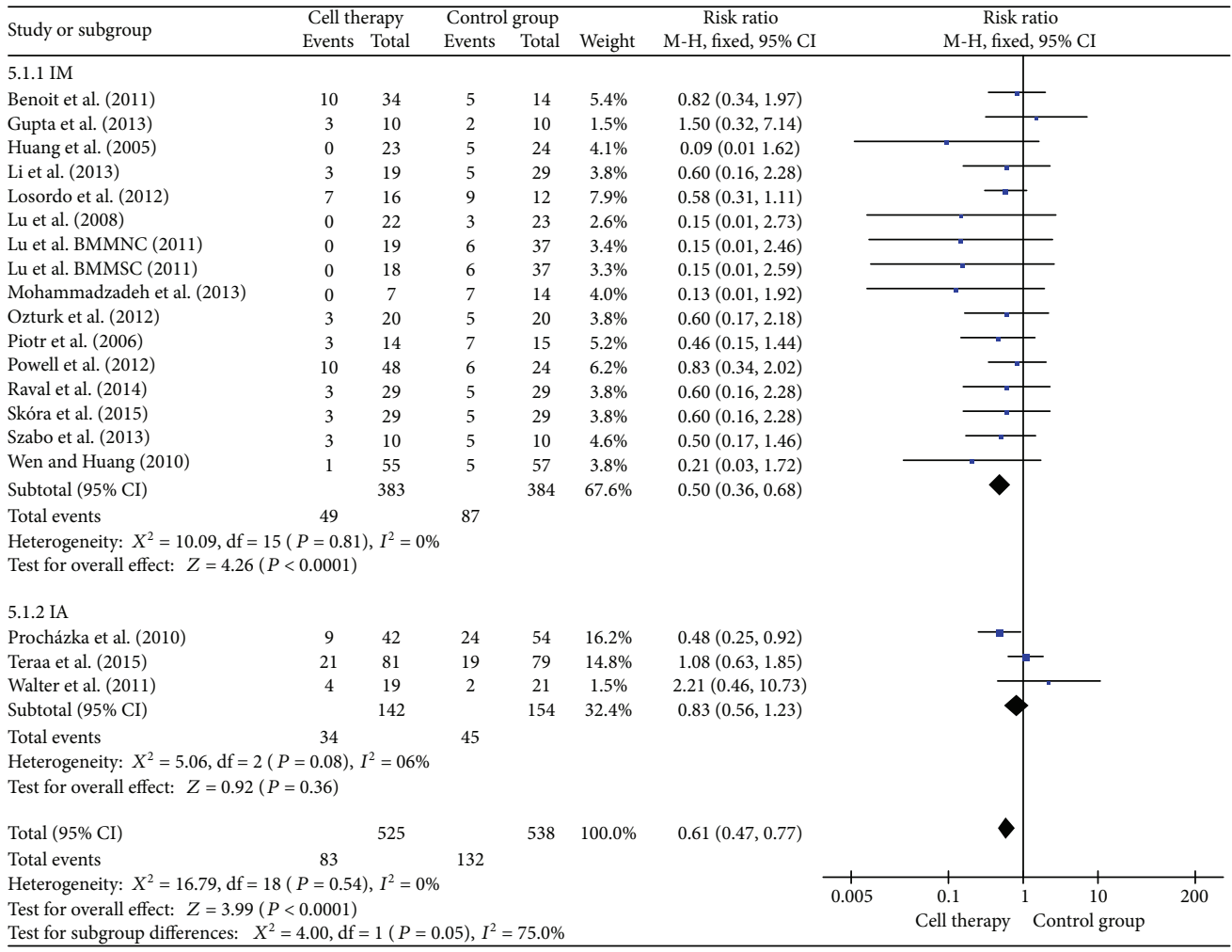

(b)

FIgURE 2: Forest plot of meta-analysis of the amputation rate in cell therapy and standard care for critical limb ischemia. (a) Subgroup analyses of bone marrow stem cells (BMSCs) versus peripheral blood stem cells (PBSCs). (b) Subgroup analyses of intramuscular (IM) versus intra-arterial (IA). Squares indicate the risk ratio, and horizontal lines represent $95 \%$ confidence intervals. 


\begin{tabular}{|c|c|c|c|c|c|c|c|c|c|c|}
\hline \multirow{3}{*}{$\frac{\text { Study or subgroup }}{2.1 .1 \text { BMSCs }}$} & \multicolumn{2}{|c|}{ Cell therapy } & \multicolumn{2}{|c|}{ Control group } & & \multirow{2}{*}{$\begin{array}{c}\text { Risk ratio } \\
\text { M-H, fixed, } 95 \% \mathrm{CI}\end{array}$} & \multirow{2}{*}{\multicolumn{4}{|c|}{$\begin{array}{c}\text { Risk ratio } \\
\text { M-H, fixed, } 95 \% \mathrm{CI}\end{array}$}} \\
\hline & \multirow[t]{2}{*}{ Events } & \multirow[t]{2}{*}{ Total } & \multirow[t]{2}{*}{ Events } & \multirow[t]{2}{*}{ Total } & & & & & & \\
\hline & & & & & Weight & & & \\
\hline Arai et al. (2006) & 3 & 8 & 1 & 6 & $1.1 \%$ & $2.25(0.30,16.63)$ & & & & \\
\hline Benoit et al. (2011) & 4 & 23 & 1 & 7 & $1.5 \%$ & $1.22(0.16,9.19)$ & & & & \\
\hline Dash et al. (2009) & 9 & 12 & 3 & 12 & $3.0 \%$ & $3.00(1.07,8.43)$ & & & & \\
\hline Gupta et al. (2013) & 6 & 7 & 6 & 6 & $6.9 \%$ & $0.88(0.59,1.29)$ & & - & - & \\
\hline Jain et al. (2011) & 10 & 23 & 7 & 24 & $6.8 \%$ & $1.49(0.68,3.25)$ & & & - & \\
\hline Li et al. (2013) & 5 & 19 & 0 & 17 & $0.5 \%$ & $9.90(0.59,166.78)$ & & & & \\
\hline Lu et al. (2008) & 15 & 18 & 9 & 20 & $8.5 \%$ & $1.85(1.09,3.14)$ & & & $\longrightarrow$ & \\
\hline Lu et al. BMMNC (2011) & 11 & 11 & 11 & 21 & $8.1 \%$ & $1.83(1.21,2.78)$ & & & $\longrightarrow$ & \\
\hline Lu et al. BMMSC (2011) & 6 & 11 & 2 & 21 & $1.4 \%$ & $5.73(1.38,23.80)$ & & & & \\
\hline Piotr et al. (2006) & 5 & 14 & 1 & 15 & $1.0 \%$ & $5.36(0.71,40.37)$ & & & & \\
\hline Procházka et al. (2010) & 4 & 13 & 1 & 8 & $1.2 \%$ & $2.46(0.33,18.31)$ & & & & \\
\hline Shi et al. (2009) & 18 & 25 & 15 & 25 & $15.0 \%$ & $1.20(0.80,1.80)$ & & & - & \\
\hline Teraa et al. (2015) & 19 & 51 & 15 & 50 & $15.1 \%$ & $1.24(0.71,2.16)$ & & & & \\
\hline Subtotal (95\% CI) & & 235 & & 232 & $70.3 \%$ & $1.68(1.36,2.08)$ & & & $\nabla$ & \\
\hline Total events & 115 & & 72 & & & & & & & \\
\hline \multicolumn{11}{|c|}{ Heterogeneity: $X^{2}=22.16, \mathrm{df}=12(P=0.04), I^{2}=46 \%$} \\
\hline \multicolumn{11}{|c|}{ Test for overall effect: $Z=4.85(P<0.00001)$} \\
\hline \multicolumn{11}{|l|}{ 2.1.2 PBSCs } \\
\hline Huang et al. (2005) & 14 & 18 & 7 & 18 & $7.0 \%$ & $2.00(1.07,3.75)$ & & & & \\
\hline Mohammadzadeh et al. (2013) & 6 & 7 & 4 & 14 & $2.7 \%$ & $3.00(1.24,7.25)$ & & & & \\
\hline Ozturk et al. (2012) & 5 & 9 & 0 & 8 & $0.5 \%$ & $9.90(0.63,155.08)$ & & & & \\
\hline Szabo et al. (2013) & 6 & 8 & 1 & 7 & $1.1 \%$ & $5.25(0.82,33.66)$ & & & & \\
\hline Wen and Huang (2010) & 28 & 40 & 15 & 25 & $18.4 \%$ & $1.17(0.80,1.70)$ & & & - & \\
\hline Subtotal $(95 \% \mathrm{CI})$ & & 82 & & 72 & $29.7 \%$ & $1.83(1.34,2.49)$ & & & 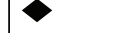 & \\
\hline Total events & 59 & & 27 & & & & & & & \\
\hline \multicolumn{11}{|c|}{ Heterogeneity: $X^{2}=9.38, \mathrm{df}=4(P=0.05), I^{2}=57 \%$} \\
\hline \multicolumn{11}{|c|}{ Test for overall effect: $Z=3.83(P=0.0001)$} \\
\hline Total $(95 \% \mathrm{CI})$ & & 317 & & 304 & $100.0 \%$ & $1.73(1.45,2.06)$ & & & 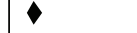 & \\
\hline Total events & 174 & & 99 & & & & & & & \\
\hline \multicolumn{7}{|c|}{ Heterogeneity: $X^{2}=31.95, \mathrm{df}=17(P=0.02), I^{2}=47 \%$} & 0.01 & 0.1 & $1 \quad 10$ & 100 \\
\hline \multicolumn{7}{|c|}{$\begin{array}{l}\text { Test for overall effect: } Z=6.16(P<0.00001) \\
\text { Test for subgroup differences: } X^{2}=0.19, \mathrm{df}=1(P=0.67\end{array}$} & \multicolumn{4}{|c|}{ Control group Cell therapy } \\
\hline
\end{tabular}

(a)

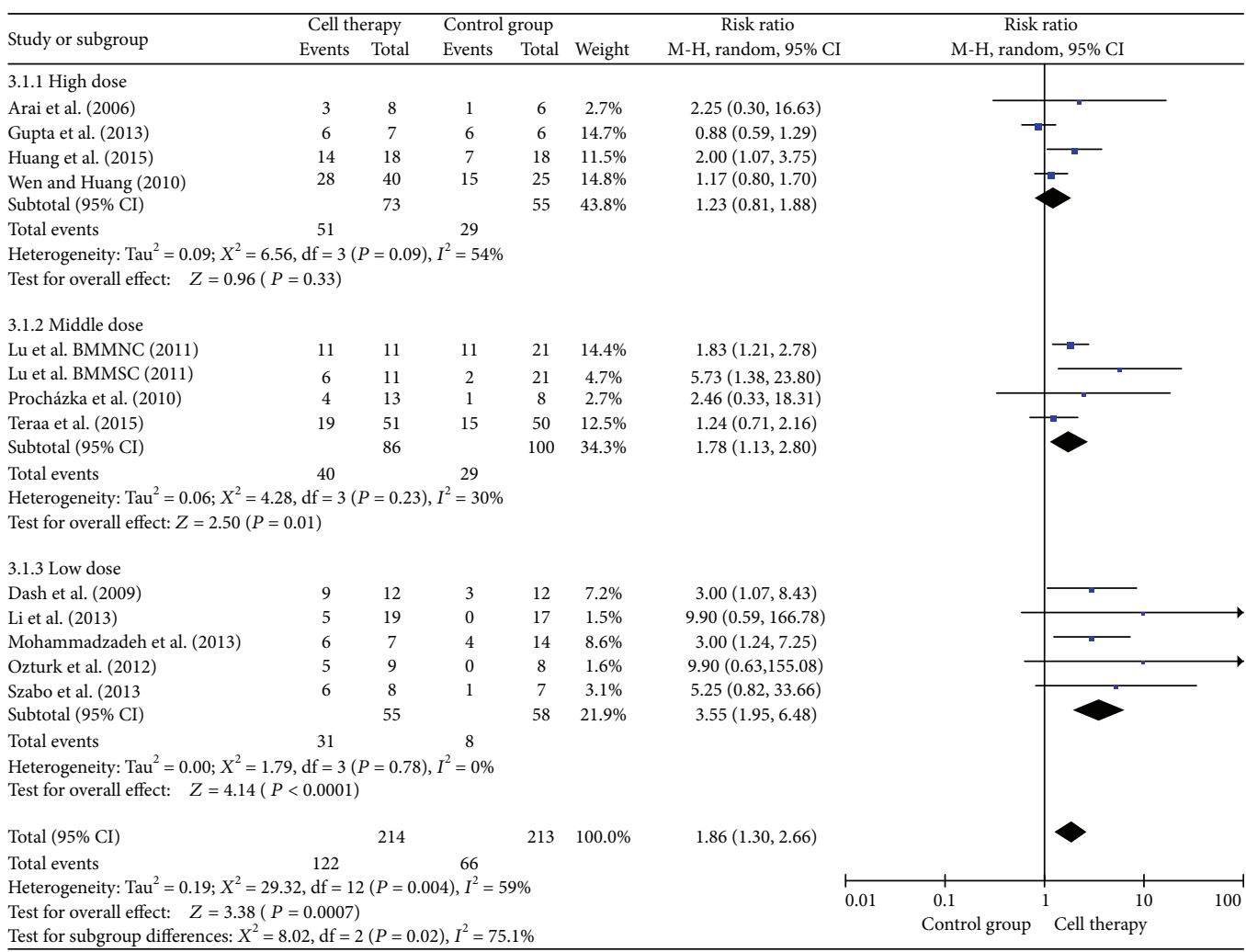

(b)

Figure 3: Forest plot of meta-analysis of ulcer healing in cell therapy and standard care for critical limb ischemia. (a) Subgroup analyses of bone marrow stem cells (BMSCs) versus peripheral blood stem cells (PBSCs). (b) Subgroup analyses among high dose (10 $)$, medium dose $\left(10^{8}\right)$, and low dose $\left(10^{7}\right)$. Squares indicate the risk ratio, and horizontal lines represent $95 \%$ confidence intervals. 


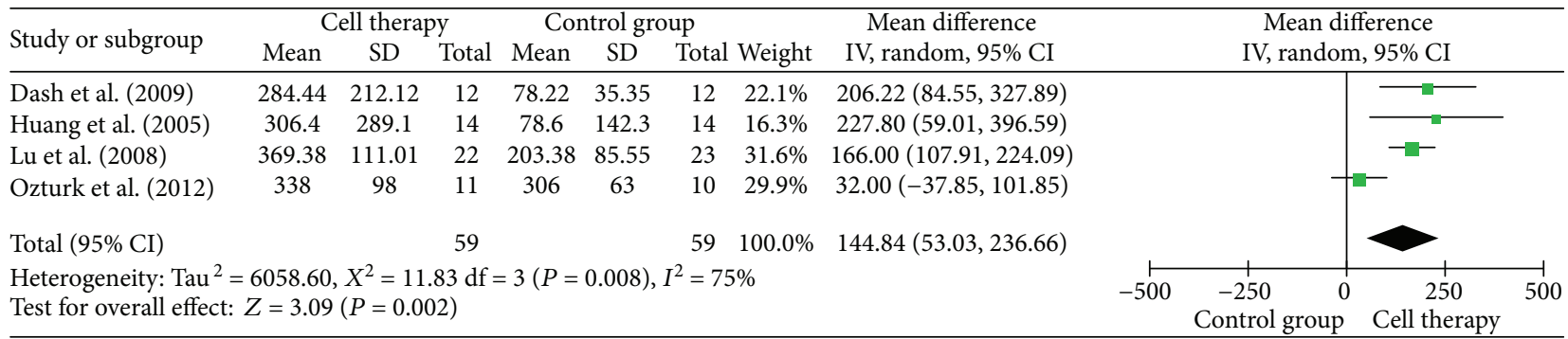

FIGURE 4: Forest plot of meta-analysis of pain-free walking distance in cell therapy and standard care for critical limb ischemia. Squares indicate the weighted mean difference, and horizontal lines represent $95 \%$ confidence intervals.

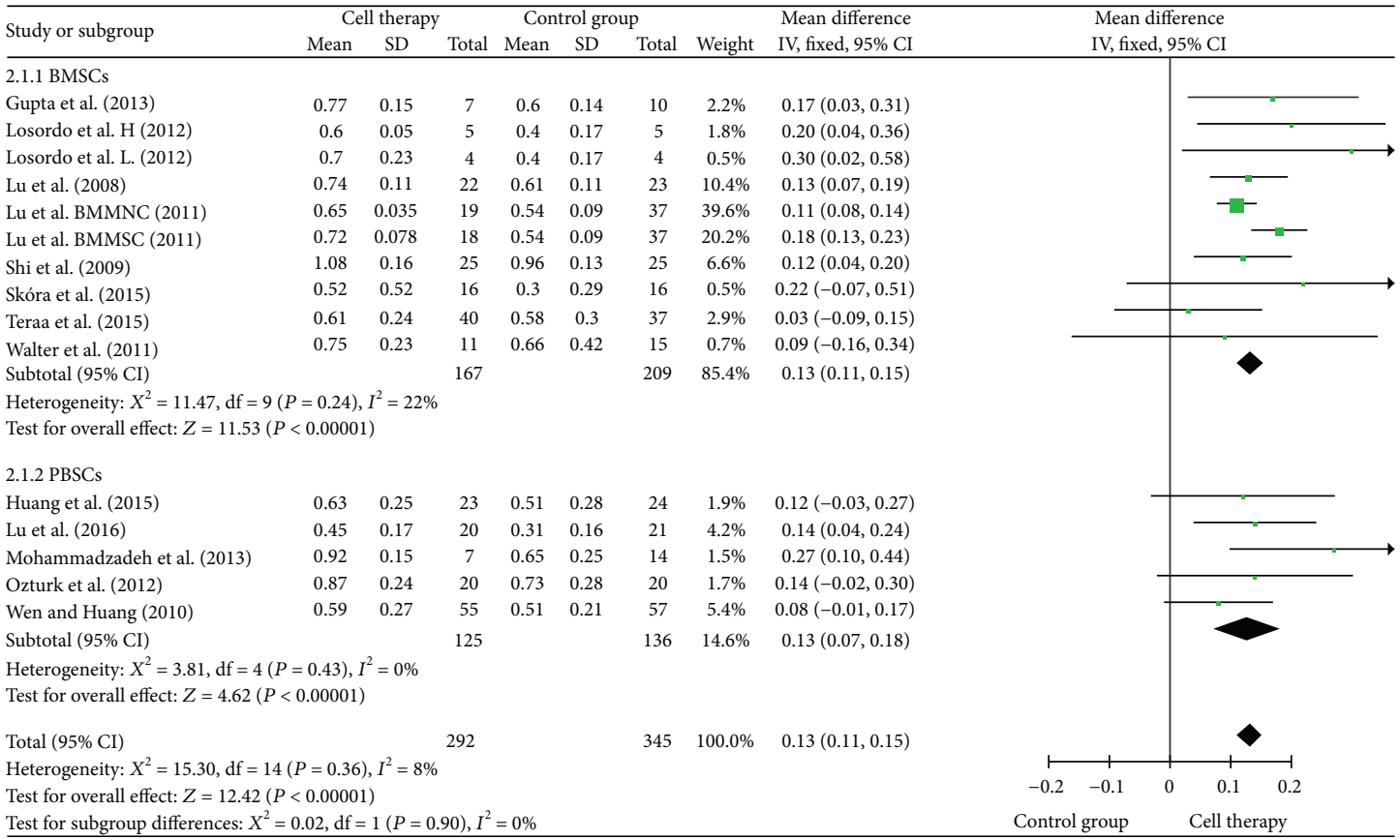

(a)

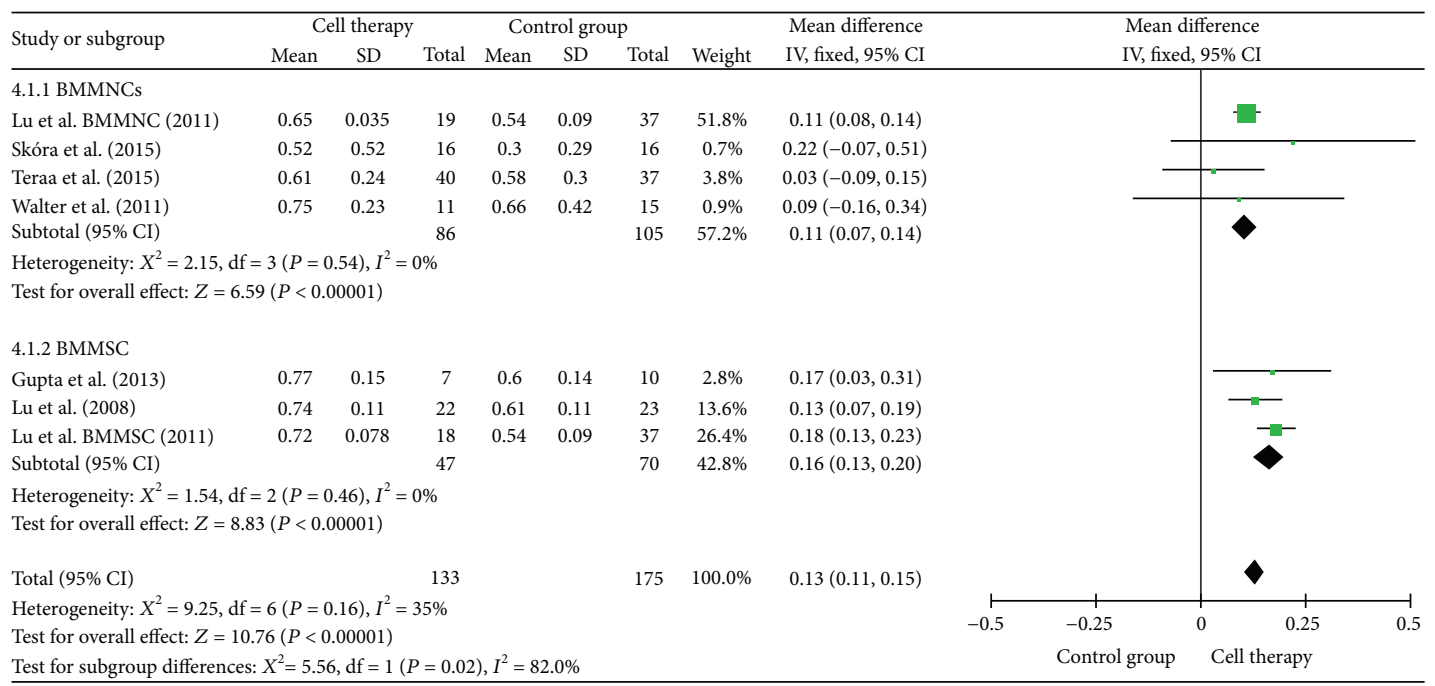

(b)

FIGURE 5: Forest plot of meta-analysis with the ankle-brachial index (ABI) in cell therapy and standard care for critical limb ischemia. (a) Subgroup analyses of bone marrow stem cells (BMSCs) versus peripheral blood stem cells (PBSCs). (b) Subgroup analyses among bone marrow mononuclear cells (BMMNCs) and bone marrow mesenchymal stem cells (BMMSCs). Squares indicate the weighted mean difference, and horizontal lines represent $95 \%$ confidence intervals. 


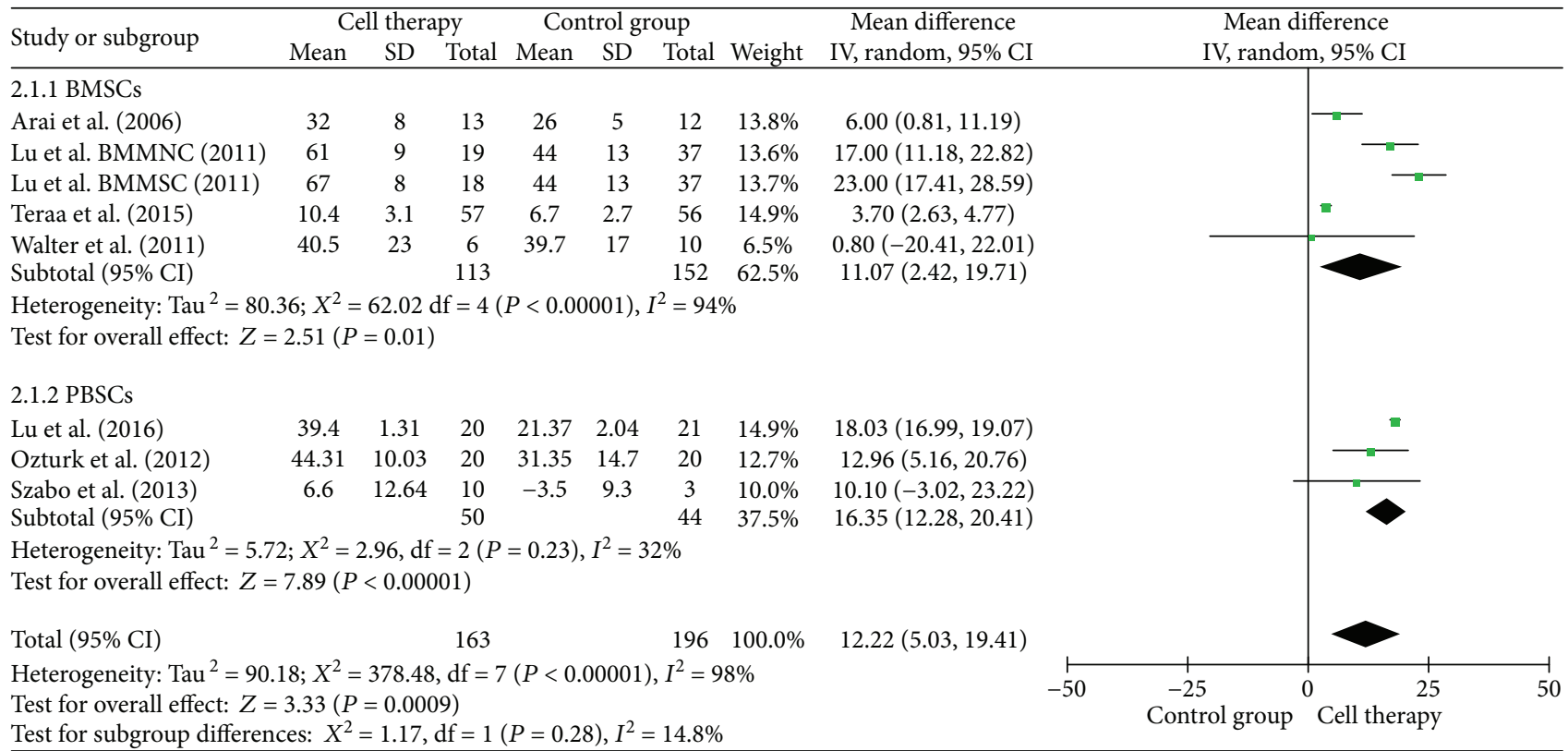

FIGURE 6: Forest plot of meta-analysis with transcutaneous oxygen tension $\left(\mathrm{TcO}_{2}\right)$ in cell therapy and standard care for critical limb ischemia. Subgroup analyses of bone marrow stem cells (BMSCs) versus peripheral blood stem cells (PBSCs). Squares indicate the weighted mean difference, and horizontal lines represent $95 \%$ confidence intervals.

\begin{tabular}{|c|c|c|c|c|c|c|c|c|c|c|}
\hline \multirow{2}{*}{ Study or subgroup } & \multicolumn{2}{|c|}{ Cell therapy } & \multicolumn{2}{|c|}{ Control group } & \multirow[b]{2}{*}{ Weight } & Risk ratio & \multirow{2}{*}{\multicolumn{3}{|c|}{$\begin{array}{c}\text { Risk ratio } \\
\mathrm{M}-\mathrm{H} \text {, random, } 95 \% \mathrm{CI} \\
\end{array}$}} & \\
\hline & Events & Total & Events & Total & & $\mathrm{M}-\mathrm{H}$, random, $95 \% \mathrm{CI}$ & & & & \\
\hline Huang et al. (2005) & 10 & 13 & 2 & 11 & $17.0 \%$ & $4.23(1.17,15.35)$ & & & $\longrightarrow$ & \\
\hline Lu et al. (2008) & 11 & 15 & 2 & 14 & $16.7 \%$ & $5.13(1.37,19.19)$ & & & & \\
\hline Lu et al. BMMNC (2011) & 8 & 19 & 0 & 37 & $7.1 \%$ & $32.30(1.96,531.32)$ & & & & \\
\hline Lu et al. BMMSC (2011) & 15 & 18 & 0 & 37 & $7.2 \%$ & $62.00(3.92,981.34)$ & & & & \\
\hline Ozturk et al. (2012) & 9 & 20 & 5 & 20 & $21.1 \%$ & $1.80(0.73,4.43)$ & & & & \\
\hline Procházka et al. (2010) & 4 & 42 & 0 & 54 & $6.7 \%$ & $11.51(0.64,208.04)$ & & & & \\
\hline Skóra et al. (2015) & 12 & 16 & 0 & 16 & $7.3 \%$ & $25.00(1.61,389.35)$ & & & & \\
\hline Wen et al. (2010) & 7 & 10 & 2 & 9 & $17.0 \%$ & $3.15(0.87,11.42)$ & & & & \\
\hline Total $(95 \%$ CI $)$ & & 153 & & 198 & $100.0 \%$ & $5.91(2.49,14.02)$ & & & & \\
\hline Total events & 76 & & 11 & & & & & & & \\
\hline \multirow{2}{*}{\multicolumn{7}{|c|}{$\begin{array}{l}\text { Heterogeneity: } \text { Tau }^{2}=0.71, X^{2}=14.55, \mathrm{df}=7(P=0.04), I^{2}=52 \% \\
\text { Test for overall effect: } Z=4.04(P<0.0001)\end{array}$}} & 0.001 & 0.1 & $1 \quad 10$ & 1000 \\
\hline & & & & & & & & Control group & Cell therapy & \\
\hline
\end{tabular}

FIGURE 7: Forest plot of meta-analysis with angiogenesis in cell therapy and standard care for critical limb ischemia. Squares indicate the risk ratio, and horizontal lines represent $95 \%$ confidence intervals.

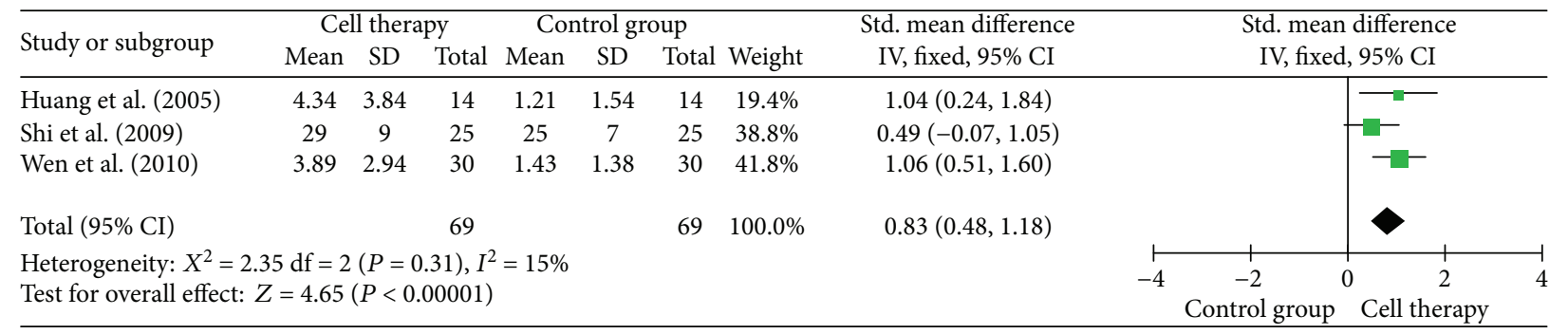

FIGURE 8: Forest plot of meta-analysis with blood flow of 10 toes in cell therapy and standard care for critical limb ischemia. Squares indicate the standardized mean difference, and horizontal lines represent $95 \%$ confidence intervals.

JUVENTAS trial is the largest RCT to investigate the effects of BMMNCs by intra-arterial [5]. The study [5] reported that repetitive intra-arterial of autologous BMMNCs was not effective in reducing the primary outcome of the amputation rate at 6 months, $\mathrm{ABI}$, ulcer healing, and $\mathrm{TcO}_{2}$. Therefore, we suggest that stem cell administration is suitable and beneficial 


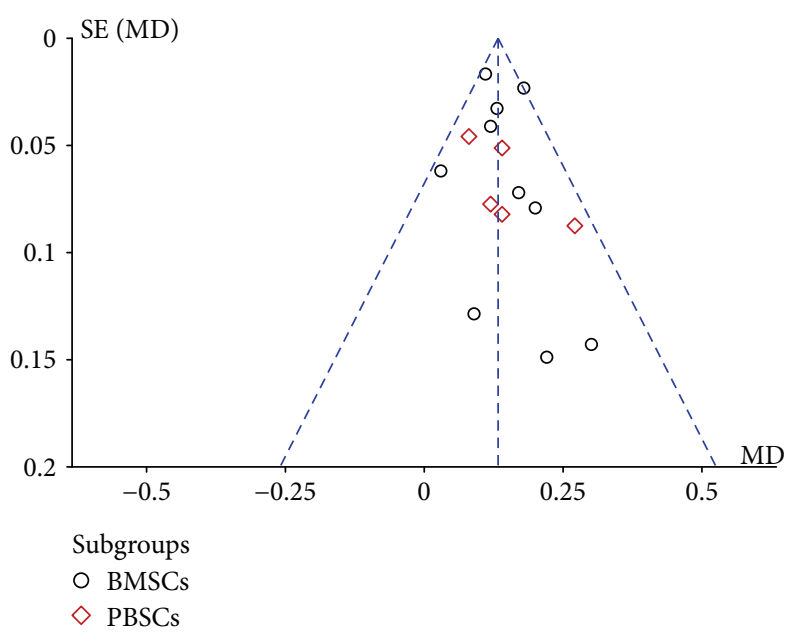

(a)

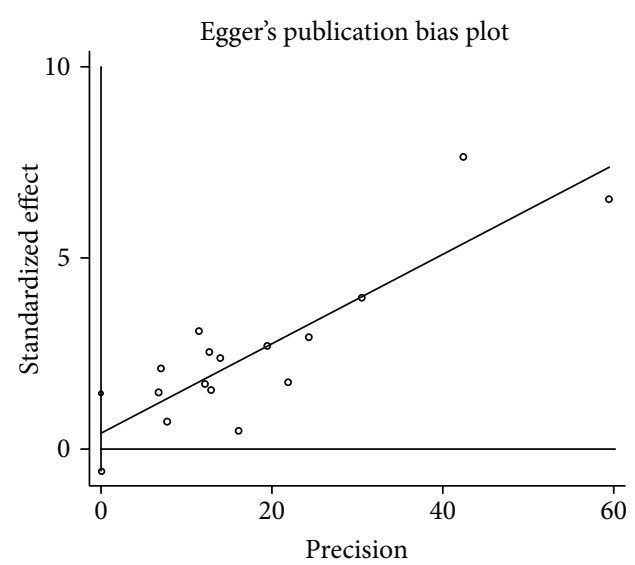

(b)

Figure 9: Meta-analysis of publication bias of the ankle-brachial index (ABI) in cell therapy and standard care for critical limb ischemia. (a) Funnel plot of the ABI. (b) Egger's funnel plot of the ABI.

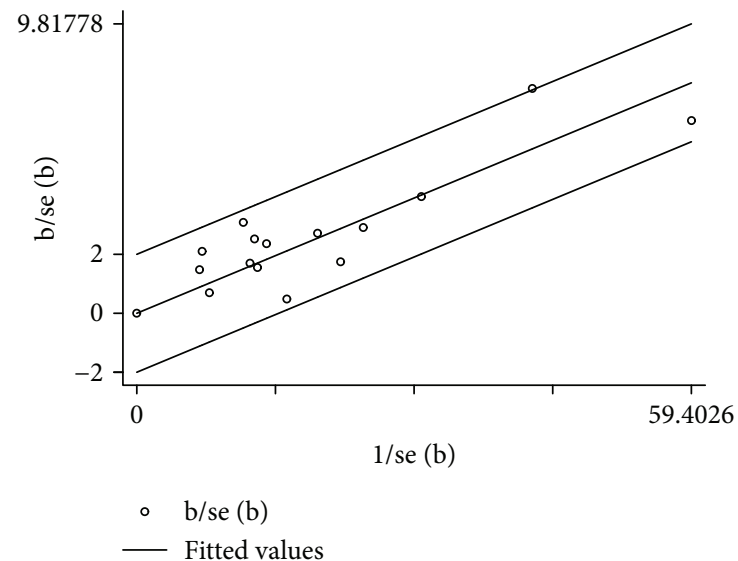

(a)

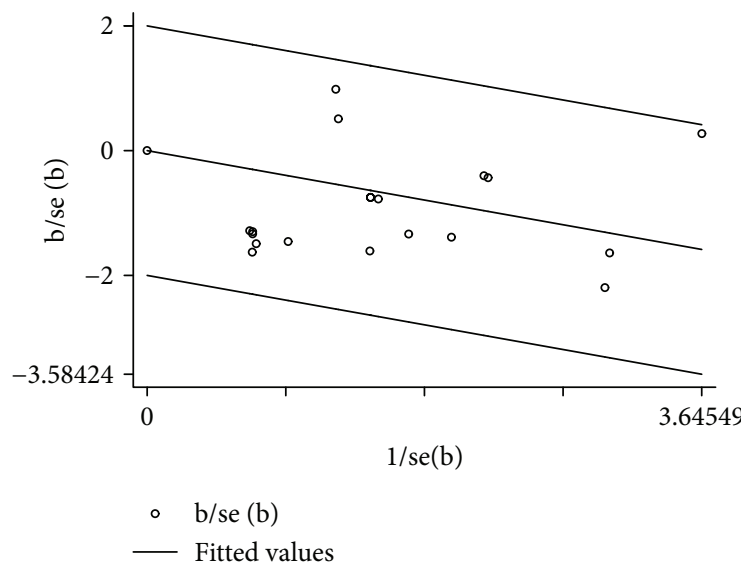

(b)

Figure 10: Meta-analysis of sensitivity in cell therapy and standard care for critical limb ischemia. (a) Galbraith plot of the ankle-brachial index (ABI). (b) Galbraith plot of the amputation rate.

choice by intramuscular injection. In addition, we found that the low dose $\left(10^{7}\right)$ group was a significant difference on the amputation rate compared with high dose $\left(10^{9}\right)$ and medium dose $\left(10^{8}\right)$ groups $(P=0.03)$, and cell therapy with low dose $\left(10^{7}\right)$ significantly reduced the amputation rate. The cell therapy with low dose $\left(10^{7}\right)$ showed a significant improvement in ulcer healing in patients with CLI $[26,31,32]$. However, a degree of heterogeneity may be generated in subgroup analysis, which could negatively impinge upon the assessment on efficacy of cell therapy. The generated heterogeneity could mask the true effect of cell therapy [10]. So we think that the results of subgroup analysis need the large clinical trials as evidence to support.

4.3. Safety. The studies of 23 RCTs showed that cell therapy was relatively safe, and the adverse events were mostly mild and transient. Teraa et al. [5] reported that there was a patient with inguinal hematoma due to intra-arterial injection, and the study of Szabo et al. [33] found that the cell therapy group had three adverse events during 3 months, but there was no evidence that the adverse events were attributed to stem cell transplantation. Li et al. [26] reported that there are three patients with fever in the cell therapy group, and they were cured after treatment. Lu et al. [15] showed that a few patients had a short-term response of mild pain 2 hours after cell transplantation, but no complications were detected, such as immune rejection and allergic reactions. Wen and Huang [34] reported that some patients felt uncomfortable of their limbs after intramuscular injection of PBSCs within 1 week, and the intramuscular injection site did not appear infected during 3-month follow-up. Similarly, many studies reported that stem cell transplantation was safe in long-term follow-up [28, 35]. The study by Molavi et al. [36] showed no adverse events during the 24-week follow-up period after cell delivery. No serious adverse events were found in the 23 studies included in this meta-analysis. Therefore, autologous stem cell transplantation is safe in the treatment of CLI. 
In conclusion, this meta-analysis suggests that autologous stem cell therapy is safe and effective in CLI. Subgroup analysis indicates that cell types, cell dosage, route of administration, and follow-up time are the very important factors in stem cell therapy. However, we still lack high quality and large scale of RCTs to explore the influence of factors and the effect of autologous stem cell therapy in CLI.

\section{Conflicts of Interest}

The authors declare that they have no competing interests.

\section{Authors' Contributions}

Baocheng Xie and Daohua Xu designed the research. Baocheng Xie, Houlong Luo, Yusheng Zhang, Qinghui Wang, and Chenhui Zhou reviewed the literatures. Baocheng Xie, Houlong Luo, Yusheng Zhang, Qinghui Wang, and Chenhui Zhou collected the data. Baocheng Xie, Houlong Luo, and Yusheng Zhang analyzed the data. Baocheng Xie and Daohua $\mathrm{Xu}$ wrote the paper.

\section{Acknowledgments}

This research was supported by Natural Science Foundation of Guangdong Province (2014A030313534) and Social Science and Technology Development Project of Dongguan (2014108101052).

\section{References}

[1] R. W. Sprengers, M. Teraa, F. L. Moll, G. Ardine de Wit, Y. van der Graaf, and M. C. Verhaar, "Quality of life in patients with no-option critical limb ischemia underlines the need for new effective treatment," Journal of Vascular Surgery, vol. 52, no. 4, pp. 843-849.e1, 2010.

[2] Á. Cequier, C. Carrascosa, E. Diez-Tejedor et al., "Comments on the ESC guidelines on the diagnosis and treatment of peripheral artery diseases. A report of the Task Force of the Clinical Practice Guidelines Committee of the Spanish Society of Cardiology," Revista Española de Cardiología (English Edition), vol. 65, no. 2, pp. 119-124, 2012.

[3] L. Norgren, W. R. Hiatt, J. A. Dormandy, M. R. Nehler, K. A. Harris, and F. G. R. Fowkes, "Inter-society consensus for the management of peripheral arterial disease (TASC II)," Journal of Vascular Surgery, vol. 45, no. 1, pp. S5-S67, 2007.

[4] M. R. Nehler, S. Duval, L. Diao et al., "Epidemiology of peripheral arterial disease and critical limb ischemia in an insured national population," Journal of Vascular Surgery, vol. 60, no. 3, pp. 686-695.e2, 2014.

[5] M. Teraa, R. W. Sprengers, R. E. G. Schutgens et al., "Effect of repetitive intra-arterial infusion of bone marrow mononuclear cells in patients with no-option limb ischemia: the randomized, double-blind, placebo-controlled rejuvenating endothelial progenitor cells via transcutaneous intra-arterial supplementation (JUVENTAS) trial," Circulation, vol. 131, no. 10, pp. 851-860, 2015.

[6] S. D. Patel, L. Biasi, I. Paraskevopoulos et al., "Comparison of angioplasty and bypass surgery for critical limb ischaemia in patients with infrapopliteal peripheral artery disease," British Journal of Surgery, vol. 103, no. 13, pp. 1815-1822, 2016.
[7] M. Pave, L. Benadiba, L. Berger, D. Gouicem, M. Hendricks, and D. Plissonnier, "Below-the-knee angioplasty for critical limb ischemia: results of a series of 157 procedures and impact of the angiosome concept," Annals of Vascular Surgery, vol. 36, pp. 199-207, 2016.

[8] F. Becker, H. Robert-Ebadi, J. B. Ricco et al., "Chapter I: definitions, epidemiology, clinical presentation and prognosis," European Journal of Vascular and Endovascular Surgery, vol. 42, pp. S4-S12, 2011.

[9] A. N. Raval, E. G. Schmuck, G. Tefera et al., "Bilateral administration of autologous CD133+ cells in ambulatory patients with refractory critical limb ischemia: lessons learned from a pilot randomized, double-blind, placebo-controlled trial," Cytotherapy, vol. 16, no. 12, pp. 1720-1732, 2014.

[10] M. Rigato, M. Monami, and G. P. Fadini, "Autologous cell therapy for peripheral arterial disease: systematic review and meta-analysis of randomized, non-randomized, and noncontrolled studies," Circulation Research, vol. 120, no. 8, pp. 1326-1340, 2017.

[11] R. Compagna, B. Amato, S. Massa et al., "Cell therapy in patients with critical limb ischemia," Stem Cells International, vol. 2015, Article ID 931420, 13 pages, 2015.

[12] B. Lehalle, "Stem cells as a new treatment for peripheral artery disease: hype or hope? The point of view of a vascular surgeon," Bio-medical Materials and Engineering, vol. 25, 1 Supplement, pp. 73-78, 2015.

[13] M. Dubsky, A. Jirkovska, R. Bem et al., "Both autologous bone marrow mononuclear cell and peripheral blood progenitor cell therapies similarly improve ischaemia in patients with diabetic foot in comparison with control treatment," Diabetes/Metabolism Research and Reviews, vol. 29, no. 5, pp. 369-376, 2013.

[14] E. Tateishi-Yuyama, H. Matsubara, T. Murohara et al., "Therapeutic angiogenesis for patients with limb ischaemia by autologous transplantation of bone-marrow cells: a pilot study and a randomised controlled trial," The Lancet, vol. 360, no. 9331, pp. 427-435, 2002.

[15] D. Lu, B. Chen, Z. Liang et al., "Comparison of bone marrow mesenchymal stem cells with bone marrow-derived mononuclear cells for treatment of diabetic critical limb ischemia and foot ulcer: a double-blind, randomized, controlled trial," Diabetes Research and Clinical Practice, vol. 92, no. 1, pp. 26-36, 2011.

[16] C. A. Hart, J. Tsui, A. Khanna, D. J. Abraham, and D. M. Baker, "Stem cells of the lower limb: their role and potential in management of critical limb ischemia," Experimental Biology and Medicine, vol. 238, no. 10, pp. 1118-1126, 2013.

[17] M. Yang, L. Sheng, T. R. Zhang, and Q. Li, "Stem cell therapy for lower extremity diabetic ulcers: where do we stand?," BioMed Research International, vol. 2013, Article ID 462179, 8 pages, 2013.

[18] S. M. O. Peeters Weem, M. Teraa, G. J. de Borst, M. C. Verhaar, and F. L. Moll, "Bone marrow derived cell therapy in critical limb ischemia: a meta-analysis of randomized placebo controlled trials," European Journal of Vascular and Endovascular Surgery, vol. 50, no. 6, pp. 775-783, 2015.

[19] X. Sun, J. Ying, Y. Wang et al., "Meta-analysis on autologous stem cell transplantation in the treatment of limb ischemic," International Journal of Clinical and Experimental Medicine, vol. 8, no. 6, pp. 8740-8748, 2015.

[20] D. Moher, B.'. Pham, A. Jones et al., “Does quality of reports of randomised trials affect estimates of intervention efficacy 
reported in meta-analyses?," The Lancet, vol. 352, no. 9128 , pp. 609-613, 1998.

[21] H. Lawall, P. Bramlage, and B. Amann, "Treatment of peripheral arterial disease using stem and progenitor cell therapy," Journal of Vascular Surgery, vol. 53, no. 2, pp. 445-453, 2011.

[22] M. Teraa, R. W. Sprengers, P. E. Westerweel et al., "Bone marrow alterations and lower endothelial progenitor cell numbers in critical limb ischemia patients," PLoS One, vol. 8, no. 1, article e55592, 2013.

[23] M. Arai, Y. Misao, H. Nagai et al., "Granulocyte colonystimulating factor: a noninvasive regeneration therapy for treating atherosclerotic peripheral artery disease," Circulation Journal, vol. 70, no. 9, pp. 1093-1098, 2006.

[24] P. Barć, J. Skóra, A. Pupka et al., "Bone-marrow cells in therapy of critical limb ischemia of lower extremities-own experience," Acta Angiologica, vol. 12, no. 4, pp. 155-166, 2006.

[25] D. H. Walter, H. Krankenberg, J. O. Balzer et al., "Intraarterial administration of bone marrow mononuclear cells in patients with critical limb ischemia: a randomized-start, placebocontrolled pilot trial (PROVASA)," Circulation: Cardiovascular Interventions, vol. 4, no. 1, pp. 26-37, 2011.

[26] M. Li, Department of Cardiology Provincial Hospital affiliated to Shandong University, Shandong Province, China, H. Zhou et al., "Autologous bone marrow mononuclear cells transplant in patients with critical leg ischemia: preliminary clinical results," Experimental and Clinical Transplantation, vol. 11, no. 5, pp. 435-439, 2013.

[27] M. Dubsky, A. Jirkovska, R. Bem et al., "Comparison of two different methods of stem cell therapy of critical limb ischemia in patients with diabetic foot disease," Diabetes, 2010.

[28] G. P. Lasala, J. A. Silva, P. A. Gardner, and J. J. Minguell, "Combination stem cell therapy for the treatment of severe limb ischemia: safety and efficacy analysis," Angiology, vol. 61, no. 6, pp. 551-6, 2010.

[29] P. K. Gupta, A. Chullikana, R. Parakh et al., "A double blind randomized placebo controlled phase I/II study assessing the safety and efficacy of allogeneic bone marrow derived mesenchymal stem cell in critical limb ischemia," Journal of Translational Medicine, vol. 11, no. 1, p. 143, 2013.

[30] V. Procházka, J. Gumulec, F. Jalůvka et al., "Cell therapy, a new standard in management of chronic critical limb ischemia and foot ulcer," Cell Transplantation, vol. 19, no. 11, pp. 14131424, 2010.

[31] A. Ozturk, Y. Kucukardali, F. Tangi et al., "Therapeutical potential of autologous peripheral blood mononuclear cell transplantation in patients with type 2 diabetic critical limb ischemia," Journal of Diabetes and its Complications, vol. 26, no. 1, pp. 29-33, 2012.

[32] L. Mohammadzadeh, S. H. Samedanifard, A. Keshavarzi et al., "Therapeutic outcomes of transplanting autologous granulocyte colony-stimulating factor-mobilised peripheral mononuclear cells in diabetic patients with critical limb ischaemia," Experimental and Clinical Endocrinology \& Diabetes, vol. 121, no. 1, pp. 48-53, 2013.

[33] G. V. Szabo, Z. Kovesd, J. Cserepes, J. Daroczy, M. Belkin, and G. Acsady, "Peripheral blood-derived autologous stem cell therapy for the treatment of patients with late-stage peripheral artery disease-results of the short- and long-term follow-up," Cytotherapy, vol. 15, no. 10, pp. 1245-1252, 2013.

[34] J. C. Wen and P. P. Huang, “Autologous peripheral blood mononuclear cells transplantation in treatment of 30 cases of critical limb ischemia: 3-year safety follow-up," Journal of Clinical Rehabilitative Tissue Engineering Research, vol. 14, no. 45, pp. 8526-8530, 2010.

[35] V. Ponemone, S. Gupta, D. Sethi et al., "Safety and effectiveness of bone marrow cell concentrate in the treatment of chronic critical limb ischemia utilizing a rapid point-of-care system," Stem Cells International, vol. 2017, Article ID 4137626, 16 pages, 2017.

[36] B. Molavi, M. R. Zafarghandi, E. Aminizadeh et al., "Safety and efficacy of repeated bone marrow mononuclear cell therapy in patients with critical limb ischemia in a pilot randomized controlled trial," Archives of Iranian Medicine, vol. 19, no. 6, pp. 388-396, 2016.

[37] P. Huang, S. Li, M. Han, Z. Xiao, R. Yang, and Z. C. Han, "Autologous transplantation of granulocyte colonystimulating factor-mobilized peripheral blood mononuclear cells improves critical limb ischemia in diabetes," Diabetes Care, vol. 28, no. 9, pp. 2155-2160, 2005.

[38] L. Debin, J. Youzhao, L. Ziwen, L. Xiaoyan, Z. Zhonghui, and C. Bing, "Autologous transplantation of bone marrow mesenchymal stem cells on diabetic patients with lower limb ischemia," Journal of Medical Colleges of PLA, vol. 23, no. 2, pp. 106-115, 2008.

[39] N. R. Dash, S. N. Dash, P. Routray, S. Mohapatra, and P. C. Mohapatra, "Targeting nonhealing ulcers of lower extremity in human through autologous bone marrow-derived mesenchymal stem cells," Rejuvenation Research, vol. 12, no. 5, pp. 359-366, 2009.

[40] J. Shi, Z. R. Yang, X. Hu, L. H. Cao, X. Y. Zhang, and X. X. Ma, "Clinical study of autologous bone marrow hematopoietic stem cell transplantation for treatment of diabetic lower limb vascular lesions," Chinese Journal of Postgraduates of Medicine, vol. 32, no. 12, pp. 50-52, 2009.

[41] P. Jain, B. Perakath, M. R. Jesudason, and S. Nayak, "The effect of autologous bone marrow-derived cells on healing chronic lower extremity wounds: results of a randomized controlled study," Ostomy/Wound Management, vol. 57, no. 7, pp. 3844, 2011.

[42] E. Benoit, T. F. O'Donnell, M. D. Iafrati et al., "The role of amputation as an outcome measure in cellular therapy for critical limb ischemia: implications for clinical trial design," Journal of Translational Medicine, vol. 9, no. 1, p. 165, 2011.

[43] D. W. Losordo, M. R. Kibbe, F. Mendelsohn et al., "A randomized, controlled pilot study of autologous CD34+ cell therapy for critical limb ischemia," Circulation: Cardiovascular Interventions, vol. 5, no. 6, pp. 821-830, 2012.

[44] R. J. Powell, W. A. Marston, S. A. Berceli et al., "Cellular therapy with Ixmyelocel- $T$ to treat critical limb ischemia: the randomized, double-blind, placebo-controlled RESTORE-CLI trial," Molecular Therapy, vol. 20, no. 6, pp. 1280-6, 2012.

[45] J. Skóra, A. Pupka, D. Janczak et al., "Combined autologous bone marrow mononuclear cell and gene therapy as the last resort for patients with critical limb ischemia," Archives of Medical Science, vol. 2, no. 2, pp. 325-331, 2015.

[46] A. J. Lu, J. Zhao, S. P. Zhang, D. M. Li, L. J. Zhang, and J. L. Nan, "The clinical observation of 20 cases of diabetic vascular lesion of lower limbs treated with autologous peripheral blood stem cell transplant after bone marrow mobilization," Inner Mongolia Medical Journal, vol. 48, no. 4, pp. 402-404, 2016. 


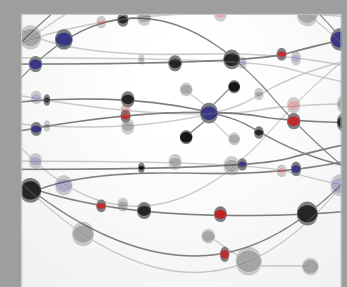

The Scientific World Journal
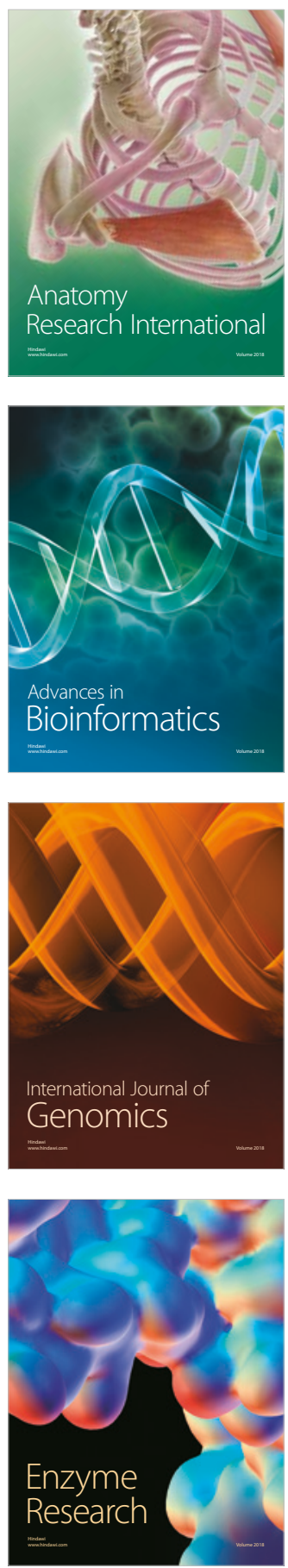
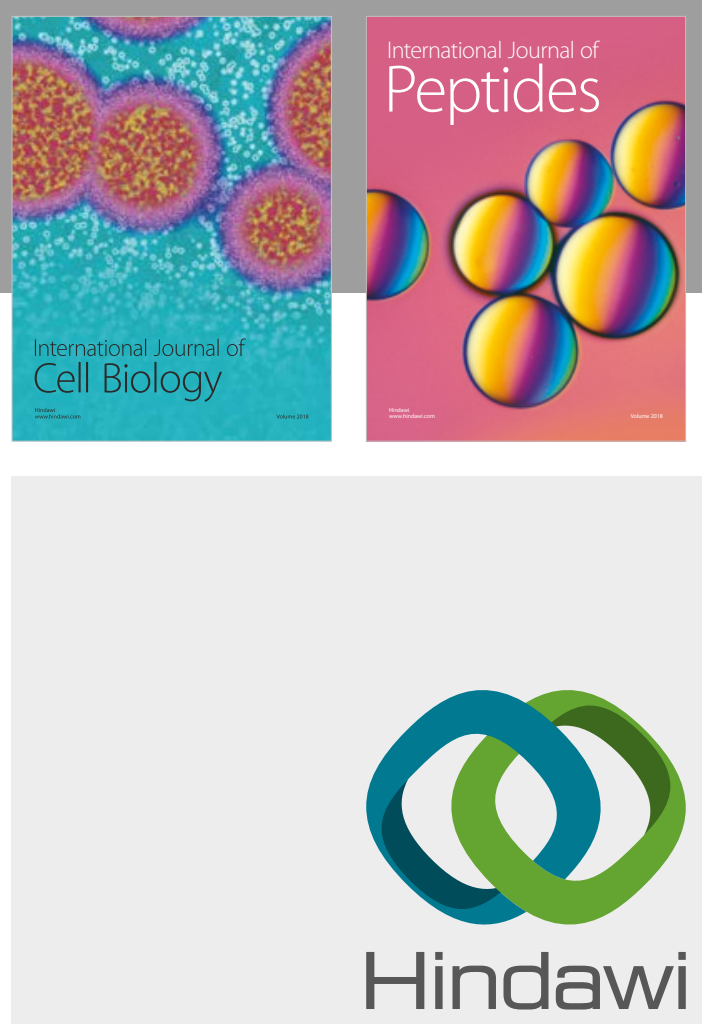

Submit your manuscripts at

www.hindawi.com
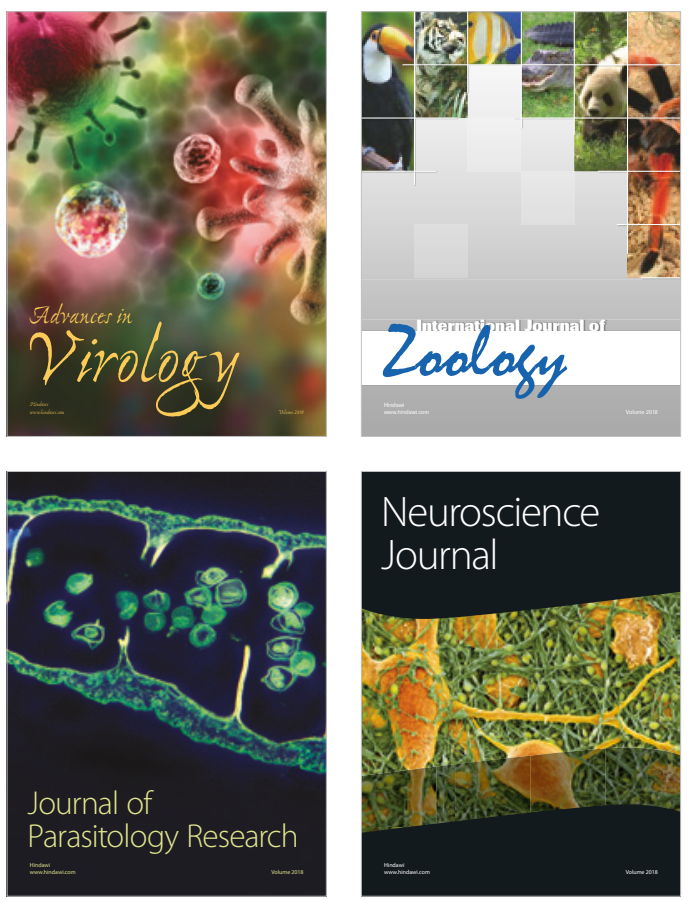
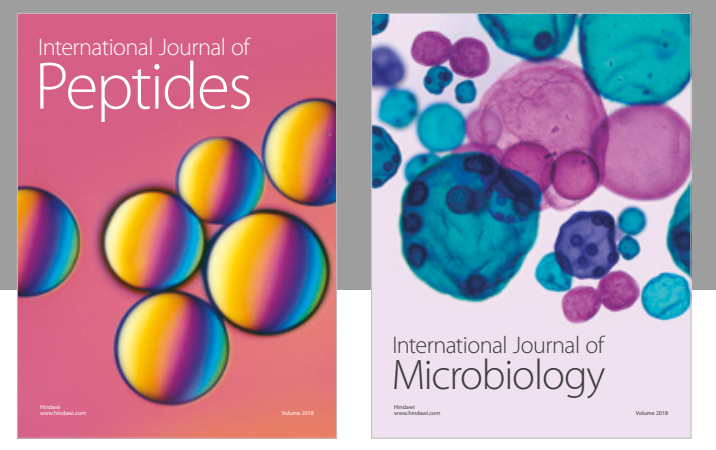

nternational Journal of Microbiology
Journal of
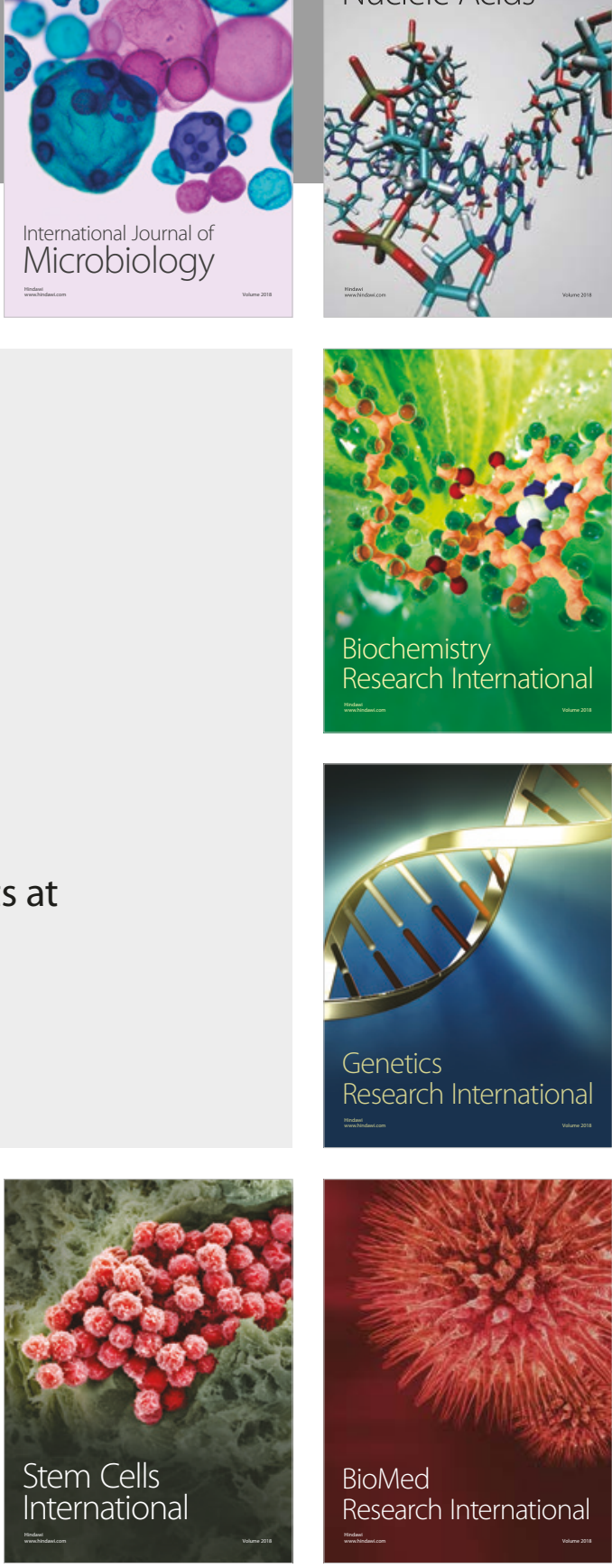
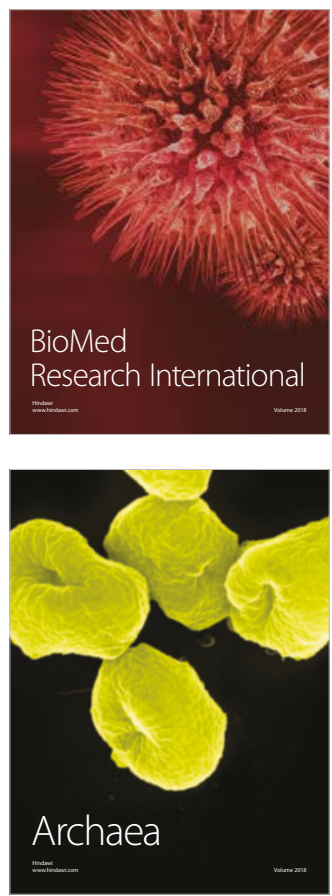